\title{
Hesperidin, A Citrus Bioflavonoid Attnuates Iron- Induced Biochemical Oxidative Stress in Mouse Liver
}

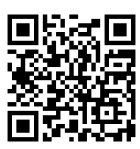

\author{
Ganesh Chandra Jagetia* and T Lalrinpuii \\ Department of Zoology, Mizoram University, Aizawl
}

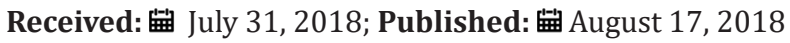

*Corresponding author: Ganesh Chandra Jagetia 10 Maharana Pratap Colony, Sector-13, Hiran Magri, Udaipur-313002, India

\begin{abstract}
Iron is an essential element, which is abundant in the red blood cells and plays a key role during oxidative phosphorylation in the mitochondria of all cells. The excess of iron has been indicated in several diseases as it induces oxidative stress. The present study was undertaken to understand the modulation of iron induce oxidative stress in mice by hesperidin. The mice were administered with $250 \mathrm{mg} / \mathrm{kg}$ body weight of hesperidin for five days before feeding with $5000,10,000$ and 20000 ppm FeCl3 for 30 days. The glutathione, glutathione-s-transferase, catalase, superoxide dismutase, lipid peroxidation, lactate dehydrogenase, aspartic acid transaminase, and alanine aminotransaminase levels were estimated in the liver of iron treated mice after 30 days post-iron treatment. The feeding of different concentrations of iron for 30 days led to an increase in the oxidative stress as indicated by a decline in the glutathione concentration, and glutathione-s-transferase, catalase, and superoxide dismutase activities accompanied by the rise in the lactate dehydrogenase, aspartic acid transaminase, and alanine aminotransaminase levels.

Treatment of hesperidin for 5 days before iron overload elevated the activities of glutathione-s-transferase, catalase, and superoxide dismutase and glutathione concentration, whereas the activities of lactate dehydrogenase, aspartic acid transaminase, and alanine aminotransaminase and lipid peroxidation declined significantly. Our study demonstrates that pre-treatment of hesperidin for five days reduced the iron induced oxidative stress indicated by the reduction in lipid peroxidation, lactate dehydrogenase, aspartic acid transaminase, and alanine aminotransaminase activities and a rise in the glutathione-s-transferase, catalase, and superoxide dismutase and glutathione contents in the mice liver.
\end{abstract}

Keywords: Mice; Liver; Antioxidants; Lipid Peroxidation; Lactate Dehydrogenase; Aspartic Acid Transaminase; Alanine Aminotransaminase

\section{Introduction}

Iron is one of the most abundant common elements on Earth Iron is a trace element and it is extremely important in carrying out various metabolic processes in all living organisms for their survival. It participates in a wide variety of metabolic processes, including oxygen transport, electron transfer, nitrogen fixation and DNA synthesis. Iron exists in two oxidative states, ferrous $\left(\mathrm{Fe}^{+2}\right)$ and ferric $\left(\mathrm{Fe}^{+3}\right)$, which can donate or accept electrons [1-3]. In addition, the iron can ligand up to six places that reduces it otherwise high reactivity. "Free" iron produces hydroxyl radicals from superoxide and hydrogen peroxide via Fenton chemistry inducing oxidative stress in the cells [4]. These free radicals produced by iron are highly reactive and they interact with proteins, DNA and lipid inflicting severe damage to these biomolecules and subsequently tissue injury [5]. Cell has got inbuilt mechanism to protect itself from oxidative stress-induced by iron. The iron is oxidized to $\mathrm{Fe}^{+3}$, which tightly combines with transferrin and is kept in a non-toxic redox-inert state [6].

In addition, two-thirds of serum transferrin exists as apo transferrin and will quickly capture the free iron which is released from the cell whenever required [7]. Iron and iron salts are poorly water soluble however, it is an essential micronutrient, which is required for numerous biological reactions including mammalian cell growth, heme and DNA biosyntheses, oxygen transport, cell proliferation, cytochrome p450 enzyme activity, and hypoxic response reactions [8]. Iron is essential constituent of numerous enzymes, including iron-sulphur and heme proteins of the respiratory chain, as well as ribonucleotide reductase, which catalyses the rate-limiting step in DNA synthesis $[9,10]$. It is common prosthetic group composed of protoporphyrin IX and a Fe (II) ion. Presence of iron is a double-edged sword, it is extremely indispensable to carry various important metabolic processes at the same time its slight excess induces oxidative stress due to production of free radicals, especially the hydroxyl radical which is highly reactive and provoke critical and even irreversible cell injury. Iron deficiency also exerts negative effects on the cells [8].

The mismanagement of iron in the cells is the principle cause of underlying pathogenic event in oxidative stress that is harbinger of several diseases $[11,12]$. The presence of excess iron in the body is referred to as iron overload. Iron -induced oxidative stress may be of several types however, the most common being the genetic. Apart from the genetic cause the presence of excess iron in the diet 
(particularly from supplement), chronic transfusion therapy, iron injections, chronic hepatitis and other disorders also lead to excess iron overload $[13,14]$. The gene mutations account for most of the iron overload in populations of northern Europe that result in an amino acid substitution at position 282 of the HFE protein. The C282Y substitution is rare outside those of white ethnicity although case reports of other mutations exist [15]. Iron overload in Asian populations is rare and it is typically due to abnormalities in nonHFE iron-related molecules [16].

The body content of iron is regulated primarily by absorption because humans have no physiological mechanism to eliminate excess iron. Accumulation of excess iron in the body may be highly toxic as it may lead to a variety of serious conditions including aging, cardiovascular diseases, gastrointestinal tract disorders, diabetes, cataractogenesis, degenerative retinal damage, autoimmune nephrotic syndromes, heavy metal toxicity, Parkinson's disease, Alzheimer's disease, bronchopulmonary dysphasia, ischemia reflow states, kidney damage, macular degeneration, stroke and cancer [17-21]. The tissue damage associated with iron overload is believed to result basically from free radical reactions mediated by iron as iron is an effective catalyst in free-radical production [22]. The natural products may be of great significance in preventing or curing iron-induced toxicity and disorders.

Hesperidin is a bioflavonoid (flavonoids have diphenol structure with the molecular formula $\mathrm{C}_{28} \mathrm{H}_{34} \mathrm{O}_{15}$ and is found in vegetables, herbs, fruits and legumes. Nearly 5000 kinds of flavonoids are known) abundantly present in citrus fruits. Its aglycone form is called hesperitin. The hesperidin derives its name from the word "hesperidium", the kind of fruit produced by citrus trees. The French chemist Lebreton (1828) was first to isolate hesperidin from the white inner layers of citrus peels. Hesperidin is believed to play a role in plant defence against fungal and bacterial invasions [23]. The sweet oranges (Citrus sinensis) and tangelos contain very high amount of hesperidin. The orange juice containing pulp has higher amount of hesperidin than the orange juice that is without pulp [24]. Hesperidin exerts a variety of pharmacological actions including anti-inflammatory, antioxidant, free radical scavenging and antiulcer effects. It also inhibits selected cytochrome p450 enzymes resulting in drug interactions [25,26]. Hesperidin increases the strength of the capillaries (blood vessels) and regulates their permeability.

It assists vitamin $\mathrm{C}$ in maintaining the collagen in healthy condition and hesperidin also helps in the proper absorption of vitamin $\mathrm{C}$. It prevents vitamin $\mathrm{C}$ from being destroyed in the body by oxidation; beneficial in hypertension; helps haemorrhages and in conditions of ruptured capillaries and connective tissues and builds a protective barrier against infections [27]. Hesperidin has been reported to be analgesic, anti-inflammatory, antiallergenic, anticancerous, antihypotensive, antimicrobial and vasodilators [28-32]. The consumption of $500 \mathrm{ml}$ orange juice for 4 weeks has been reported to modulate the expression of 3422 genes whereas only hesperidin intake led to the modulation of 1819 genes studied by microarrays [33]. Hesperidin has been found to be active against oxidative stress, hypotension, nitric oxide synthase inhibition, neurotoxicity, Herpes simplex virus infection, apoptosis, inflammatory bowel disease, arthritis, atherogenesis platelet and erythrocyte aggregation and infection [34-44]. The hesperidin has been reported to scavenge free radicals and accelerate wound healing of irradiated wounds. It was found to be non-toxic up to $2 \mathrm{~g} / \mathrm{kg}$ body weight in mice orally $[45,46]$. The sub chronic administration of $5 \%$ hesperidin for 13 weeks has been found to be non-toxic in mice [47]. The liver is an important organ that metabolizes iron therefore the present study was undertaken to obtain an insight into the effect of hesperidin on the iron-induced oxidative stress in the mouse liver.

\section{Materials and Methods}

\section{Chemicals}

Ferric chloride, Hesperidin, , di-sodium hydrogen phosphate $\left(\mathrm{Na}_{2} \mathrm{HPO}_{4}\right)$, hydrogen peroxide $\left(\mathrm{H}_{2} \mathrm{O}_{2}\right)$, di-potassium hydrogen phosphate $\left(\mathrm{K}_{2} \mathrm{HPO}_{4}\right)$, potassium di-hydrogen phosphate $\left(\mathrm{KH}_{2} \mathrm{PO}_{4}\right)$, were procured from MERC, India Ltd., Mumbai, whereas 1-chloro-2,4 dinitrobenzene (CDNB), phenazene methosulfate, nitrobluetetrazolium, sodium pyruvate, cumene hydroperoxide, thiobarbituric acid, 5-5'-dithiobis[2-nitrobenzoic acid, 5-thionitrobenzoic acid, mM tert-butyl-hydroperoxide and nicotinamide adenine dinucleotide (NADH) were supplied by the Sigma Aldrich Chemical Company, Kolkata, India

\section{Animal care and Handling}

The animal care and handling were done according to the guidelines issued by the World Health Organization, Geneva, Switzerland and the INSA (Indian National Science Academy, New Delhi, India). Usually, six to eight-week-old inbred Swiss albino mice weighing 25 to $30 \mathrm{~g}$ of either sex were selected from the inbred colony maintained under the controlled conditions of temperature $\left(23 \pm 2^{\circ} \mathrm{C}\right)$, humidity $(50 \pm 5 \%)$ and $12 \mathrm{~h}$ of light and dark cycle, respectively. The animals had free access to the standard food and water. Five animals were housed in a polypropylene cage containing wood powder (procured locally) as bedding throughout the experiment. The Animal Ethics Committee of Mizoram University, Aizawl, India had approved the study.

\section{Preparation of drug and mode of administration}

The required amount of hesperidin was dissolved in 1\% CMC in distilled water and the animals were administered with $250 \mathrm{mg} /$ $\mathrm{kg}$ body weight of hesperidin (HPD) orally through an oral gavage.

\section{Experimental}

The effect of hesperidin on iron-induced oxidative stress in the mouse liver was studied by dividing the animals into the following groups:

a) Iron: The animals of this group were administered with $0,5000,10,000$ and 20,000 ppm of ferric chloride in ordinary drinking water daily for 30 days consecutively.

b) HSP+iron: Animals of this group were orally administered with $250 \mathrm{mg} /$ body weight of hesperidin intraperitoneally for five days before administering the animals with 0,5000 , 10,000 and 20,000 ppm of ferric chloride in ordinary drinking water daily up to 30 days. 
Thirty days after the administration of Ferric chloride, the animals from both the groups were killed by cervical dislocation. The animals were dissected and perfused with ice cold saline transcardially. The liver from both group of animals was removed and blot dried. A total of 80 mice were used to complete this experiment.

\section{Preparation of Homogenate}

The liver was weighed, and $10 \%$ homogenate was prepared in a phosphate buffer saline using an electrical homogenizer (REMI India). Various biochemical parameters were estimated in the liver homogenate after 30 days of iron treatment.

\section{Total Proteins}

The total proteins were assayed by the modified method of Lowry [48].

\section{Glutathione}

The glutathione (GSH) contents were estimated by earlier described method [49] with minor modifications. Briefly, the precipitation of proteins was carried out with $0.5 \mathrm{ml}$ ice cold $10 \%$ 5-sulfosalicylic acid and kept on ice for $10 \mathrm{~min}$ and centrifuged (Sorvall Instruments RC5C, DuPont, Minnesota, USA) at $4{ }^{\circ} \mathrm{C}$ for $15 \mathrm{~min}$ at 15,000 rpm in cold. The protein free supernatant was collected and immediately mixed with $0.5 \mathrm{ml}$ of NADPH (4 mg of reduced form was dissolved in $100 \mathrm{ml}$ of $0.5 \% \mathrm{NaHCO}_{3}$ ), $0.5 \mathrm{ml}$ of glutathione reductase $(6$ units $/ \mathrm{ml}$ in $0.1 \mathrm{M}$ phosphate buffer, $\mathrm{pH}$ 7.0) and $1 \mathrm{ml}$ of $0.6 \mathrm{M}$ DTNB [prepared in $0.2 \mathrm{M}$ phosphate buffer ( $\mathrm{pH}$ 8)]. The formation of TNB was read against the blank in a UVVisible double beam spectrophotometer (Shimadzu Corporation, Tokyo, Japan) at $412 \mathrm{~nm}$. A sample lacking GSH was used as a blank. The GSH concentration has been expressed as $\mu \mathrm{mol} / \mathrm{mg}$ protein. A standard curve was plotted using different concentrations of GSH.

\section{Glutathione-S-Transferase}

The protocol described by Habig and Pabst [50] was used to measure the activity of glutathione-S-transferase (GST), where the homogenate was mixed with $0.1 \mathrm{M}$ potassium phosphate buffer, CDNB and $10 \mathrm{mM} \mathrm{GSH}$, and kept in water bath for $10 \mathrm{~min}$ at $37^{\circ} \mathrm{C}$. The absorbance was recorded at 1 min intervals against the distilled water blank at $340 \mathrm{~nm}$ using a UV-VIS spectrophotometer. The GST activity has been expressed as $\mathrm{nmol} / \mathrm{mg}$ of protein.

GST activity = Absorbance of sample - Absorbance of blank $\times$ $1000 / 9.6 \times$ Vol of sample.

\section{Catalase}

The catalytic reduction of hydrogen peroxide was used to measure the catalase activity [51], where, hydrogen peroxide was added to the tissue homogenate and the mixture was incubated at $37^{\circ} \mathrm{C}$. The hydrogen peroxide decomposition was monitored at $0.5 \mathrm{~s}, 10 \mathrm{~s}$ intervals up to $30 \mathrm{~s}$ and the absorbance was read against the phosphate buffered blank at $240 \mathrm{~nm}$ using a UV-VIS spectrophotometer. The average difference in absorbance in $30 \mathrm{~s}$ was calculated.

\section{Superoxide Dismutase}

The activity of superoxide dismutase (SOD) was determined as described earlier [52]. Briefly, the homogenate was mixed with phenazine methosulphate, nitroblue tetrazolium and NADH and incubated at $30^{\circ} \mathrm{C}$ for $90 \mathrm{sec}$. The reaction was terminated by the addition of acetic acid and n-butanol. Blank was prepared in a similar fashion without the sample and the reaction was stopped by adding acetic acid and n-butanol. The sample absorbance was read against the blank at $560 \mathrm{~nm}$ in a UV-VIS spectrophotometer.

\section{Lipid Peroxidation}

The induction of lipid peroxidation (LOO) was measured as various thiobarbituric acid reactive substances (TBARS) including malondialdehyde, lipid hydroperoxides and aldehydes in the homogenate [53]. The liver homogenate was heated with thiobarbituric acid $(0.8 \%)$, sodium dodecyl sulphate $(0.1 \%)$ and acetic acid (20\%) in a boiling water bath for $30 \mathrm{~min}$ (lipoproteins get precipitated). The resultant mixture was cooled, extracted with n-butanol-pyridine, and the absorbance of the butanol layer was recorded at $532 \mathrm{~nm}$ using UV-Visible double beam spectrophotometer. The resultant concentration of TBA reactive substances is expressed as nmol/mg protein obtained from a standard curve of tetraethoxypropane.

\section{Estimation of Lactate dehydrogenase, Aspartate transaminase and Alanine amino transaminase}

The activities of lactate dehydrogenase, aspartate transaminase and alanine amino transaminase were measured using commercially available Respons kits according to the protocol provided by the manufacturers using a Respons 910 autoanalyzer (Diagnostic Systems $\mathrm{GmbH}$, Holzheim, Germany).

\section{Statistical Analysis}

The significance between the treatments was determined using the Student's ' $t$ ' test and one-way ANOVA with Tukey's post-hoc test. A p value of $<0.05$ was considered statistically significant. The Solo 4 statistical package (BMDP Statistical Software Inc, Los Angeles, CA, USA) was used for statistical analyses.

\section{Results}

The results of all biochemical analyses are represented as mean \pm standard error of the mean in Tables 1-8 and (Figures 1-8).

Table 1: Alteration in the Iron-induced glutathione concentration ( $\mu \mathrm{mol} / \mathrm{mg}$ protein) by $250 \mathrm{mg} / \mathrm{kg}$ body weight of hesperidin in mouse liver 30 days after treatment with iron.

\begin{tabular}{|c|c|c|}
\hline $\mathrm{FeCl}_{3}$ (PPM) & Iron & Hesperidin + Iron \\
\hline 0 & $14.10 \pm 0.18$ & $11.64 \pm 0.22$ \\
\hline 5000 & $10.61 \pm 0.13^{* *}$ & $12.02 \pm 0.23^{\mathrm{b}}$ \\
\hline 10000 & $10.42 \pm 0.12^{* *}$ & $10.84 \pm 0.16$ \\
\hline 20000 & $10.27 \pm 0.08^{* *}$ & $10.60 \pm 0.13$ \\
\hline
\end{tabular}

Level of significance $={ }^{a} \mathrm{P}<0.05 ;{ }^{b} \mathrm{P}<0.01 ; \mathrm{c}<<0.001 ;{ }^{\mathrm{d}} \mathrm{P}<0.0001$ When Iron group compared with Hesperidin + Iron group.

${ }^{*} \mathrm{P}<0.001 ;{ }^{* *} \mathrm{P}<0.0001$, Iron group compared to control. 
Table 2: Alteration in the Iron-induced glutathione-s-transferase activity (nmol/mg protein) by $250 \mathrm{mg} / \mathrm{kg}$ body weight of hesperidin in mouse liver 30 days after treatment with iron.

\begin{tabular}{|c|c|c|}
\hline $\mathrm{FeCl}_{3}$ (PPM) & Iron & Hesperidin + Iron \\
\hline 0 & $5.63 \pm 0.41$ & $4.82 \pm 0.14$ \\
\hline 5000 & $3.06 \pm 0.06^{*}$ & $3.73 \pm 0.17^{\mathrm{a}}$ \\
\hline 10000 & $2.94 \pm 0.05^{*}$ & $3.42 \pm 0.12^{\mathrm{a}}$ \\
\hline 20000 & $2.65 \pm 0.04^{*}$ & $2.85 \pm 0.20$ \\
\hline
\end{tabular}

Level of significance $={ }^{a} \mathrm{P}<0.05 ;{ }^{b} \mathrm{P}<0.01 ; \mathrm{c} P<0.001 ;{ }^{\mathrm{d}} \mathrm{P}<0.0001$ When Iron group compared with Hesperidin + Iron group.

${ }^{*} \mathrm{P}<0.01 ;{ }^{* *} \mathrm{P}<0.0001$, Iron group compared to control.

Table 3: Alteration in the Iron-induced catalase activity (nmol/ $\mathrm{mg}$ protein) by $250 \mathrm{mg} / \mathrm{kg}$ body weight of hesperidin in mouse liver 30 days after treatment with iron.

\begin{tabular}{|c|c|c|}
\hline $\mathrm{FeCl}_{3}$ (PPM) & Iron & Hesperidin + Iron \\
\hline 0 & $86.36 \pm 3.29$ & $86.33 \pm 1.79$ \\
\hline 5000 & $32.23 \pm 0.25^{* *}$ & $69.68 \pm 3.42 \mathrm{c}$ \\
\hline 10000 & $28.15 \pm 1.36^{* *}$ & $59.74 \pm 2.09 \mathrm{c}$ \\
\hline 20000 & $24.37 \pm 1.64^{* *}$ & $51.26 \pm 1.26 \mathrm{c}$ \\
\hline
\end{tabular}

Level of significance $={ }^{\mathrm{a}} \mathrm{P}<0.05 ;{ }^{\mathrm{b}} \mathrm{P}<0.01 ;{ }^{\mathrm{c}} \mathrm{P}<0.001 ;{ }^{\mathrm{d}} \mathrm{P}<0.0001$ When Iron group compared with Hesperidin + Iron group.

${ }^{*} \mathrm{P}<0.001 ;{ }^{* *} \mathrm{P}<0.0001$, Iron group compared to control

Table 4: Alteration in the Iron-induced superoxide dismutase activity (nmol/mg protein) by $250 \mathrm{mg} / \mathrm{kg}$ body weight of hesperidin in mouse liver 30 days after treatment with iron.

\begin{tabular}{|c|c|c|}
\hline $\mathrm{FeCl}_{3}$ (PPM) & Iron & Hesperidin + Iron \\
\hline 0 & $54.35 \pm 0.44$ & $51.04 \pm 0.33$ \\
\hline 5000 & $27.79 \pm 0.93^{* *}$ & $38.48 \pm 0.92^{\mathrm{c}}$ \\
\hline 10000 & $15.18 \pm 0.58^{* *}$ & $34.99 \pm 0.18^{\mathrm{d}}$ \\
\hline 20000 & $11.98 \pm 0.48^{* *}$ & $32.34 \pm 0.41^{\mathrm{d}}$ \\
\hline
\end{tabular}

Level of significance $=\mathrm{a} P<0.05$; $\mathrm{b}<0.01$; $\mathrm{c} P<0.001$; ${ }^{\mathrm{d}} \mathrm{P}<0.0001$ When Iron group compared with Hesperidin + Iron group.

${ }^{*} \mathrm{P}<0.001$; ${ }^{* *} \mathrm{P}<0.0001$, Iron group compared to control.

Table 5: Alteration in the Iron-induced lipid peroxidation (nmol/ mg protein) by $250 \mathrm{mg} / \mathrm{kg}$ body weight of hesperidin in mouse liver 30 days after treatment with iron

\begin{tabular}{|c|c|c|}
\hline $\mathrm{FeCl}_{3}$ (PPM) & Iron & Hesperidin + Iron \\
\hline 0 & $6.95 \pm 0.28$ & $6.9 \pm 0.11$ \\
\hline 5000 & $21.66 \pm 0.66^{* *}$ & $18.27 \pm 0.67^{\mathrm{d}}$ \\
\hline 10000 & $30.10 \pm 1.73^{* *}$ & $19.83 \pm 0.17^{\mathrm{d}}$ \\
\hline 20000 & $34.00 \pm 1.04^{* *}$ & $23.67 \pm 0.33^{\mathrm{d}}$ \\
\hline
\end{tabular}

Level of significance $={ }^{\mathrm{a}} \mathrm{P}<0.05 ;{ }^{\mathrm{b}} \mathrm{P}<0.01 ; \mathrm{c} P<0.001$; ${ }^{\mathrm{d}} \mathrm{P}<0.0001$ When Iron group compared with Hesperidin + Iron group.

${ }^{*} \mathrm{P}<0.001 ;{ }^{* *} \mathrm{P}<0.0001$, Iron group compared to control.
Table 6: Alteration in the Iron-induced lactate dehydrogenase activity (U/L) by $250 \mathrm{mg} / \mathrm{kg}$ body weight of hesperidin in mouse liver 30 days after treatment with iron.

\begin{tabular}{|c|c|c|}
\hline $\mathrm{FeCl}_{3}$ (PPM) & Iron & $\begin{array}{c}\text { Hesperidin }+ \\
\text { Iron }\end{array}$ \\
\hline 0 & $132.06 \pm 2.06$ & $141.34 \pm 5.15$ \\
\hline 5000 & $176.77 \pm 1.81^{* *}$ & $158.88 \pm 2.06^{\mathrm{b}}$ \\
\hline 10000 & $290.26 \pm 2.48^{* *}$ & $196.71 \pm 2.48 \mathrm{~b}$ \\
\hline 20000 & $339.10 \pm 1.37^{* *}$ & $218.73 \pm 2.06 \mathrm{~d}$ \\
\hline
\end{tabular}

Level of significance $=\mathrm{a} P<0.05 ; \mathrm{b} P<0.01 ; \mathrm{P}<0.001 ;{ }^{\mathrm{d}} \mathrm{P}<0.0001$ When Iron group compared with Hesperidin + Iron group.

${ }^{*} \mathrm{P}<0.001 ;{ }^{* *} \mathrm{P}<0.0001$, Iron group compared to control.

Table 7: Alteration in the Iron-induced Aspartate transaminase activity (U/L) by $250 \mathrm{mg} / \mathrm{kg}$ body weight of hesperidin in mouse liver 30 days after treatment with iron.

\begin{tabular}{|c|c|c|}
\hline $\mathrm{FeCl}_{3}$ (PPM) & Iron & Hesperidin + Iron \\
\hline 0 & $57.34 \pm 2.28$ & $46.25 \pm 0.97^{\mathrm{a}}$ \\
\hline 5000 & $84.99 \pm 2.10^{*}$ & $65.37 \pm 0.7^{\mathrm{c}}$ \\
\hline 10000 & $111.63 \pm 1.86^{* *}$ & $86.41 \pm 2.82^{\mathrm{b}}$ \\
\hline 20000 & $119.86 \pm 2.90^{* *}$ & $88.45 \pm 2.11^{\mathrm{c}}$ \\
\hline
\end{tabular}

Level of significance $={ }^{a} \mathrm{P}<0.05 ;{ }^{b} \mathrm{P}<0.01 ; \mathrm{c}<0.001$; ${ }^{\mathrm{d}} \mathrm{P}<0.0001$ When Iron group compared with Hesperidin + Iron group.

${ }^{*} \mathrm{P}<0.001 ;{ }^{* *} \mathrm{P}<0.0001$, Iron group compared to control.

Table 8: Alteration in the Iron-induced Alanine aminotransferase activity (U/L) by $250 \mathrm{mg} / \mathrm{kg}$ body weight of hesperidin in mouse liver 30 days after treatment with iron.

\begin{tabular}{|c|c|c|}
\hline $\mathrm{FeCl}_{3}$ (PPM) & Iron & Hesperidin + Iron \\
\hline 0 & $48.44 \pm 1.29$ & $44.61 \pm 0.97^{\mathrm{a}}$ \\
\hline 5000 & $69.25 \pm 1.58^{* *}$ & $65.58 \pm 1.22$ \\
\hline 1000 & $75.97 \pm 2.13^{* *}$ & $69.25 \pm 0.89^{\mathrm{b}}$ \\
\hline 20000 & $84.74 \pm 1.07^{* *}$ & $79.52 \pm 0.74^{\mathrm{c}}$ \\
\hline
\end{tabular}

Level of significance $={ }^{a} \mathrm{p}<0.05 ;{ }^{\mathrm{b}} \mathrm{P}<0.01 ;{ }^{\mathrm{c}} \mathrm{P}<0.001 ; \mathrm{d} \mathrm{P}<0.0001$ When Iron group compared with Hesperidin + Iron group.

${ }^{*} \mathrm{P}<0.001 ;{ }^{* *} \mathrm{P}<0.0001$, Iron group compared to control.

\section{Glutathione}

The estimation of glutathione in liver revealed a spontaneous level of $14.10 \pm 0.18 \mu$ moles $/ \mathrm{mg}$ protein in control animals and administration of hesperidin alone did not reduce GSH concentration significantly when compared to non-drug treated control (Table 1). The chronic administration of ferric chloride for four weeks led to a dose dependent and significant attrition in the GSH concentration when compared to untreated control (Table 1) and (Figure 1). The Hesperidin treatment before iron overload elevated the concentration of glutathione significantly (Table 1) and (Figure 1). 


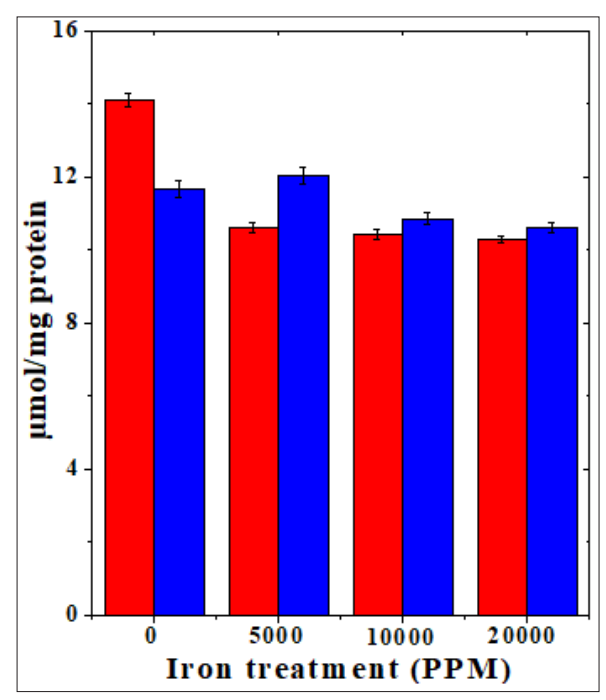

Figure 1: Effect of $250 \mathrm{mg} / \mathrm{kg}$ body weight hesperidin on the glutathione concentration in mouse liver subjected to iron overload. Red bars: Iron alone and Blue bars: Hesperidin+Iron.

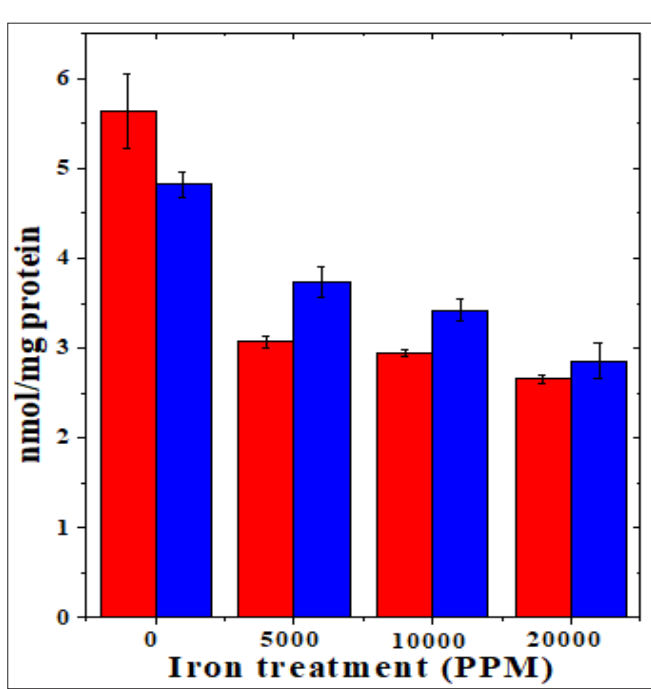

Figure 2: Effect of $250 \mathrm{mg} / \mathrm{kg}$ body weight hesperidin on the glutathione-s-transferase activity in mouse liver subjected to iron overload. Red bars: Iron alone and Blue bars: Hesperidin+Iron.

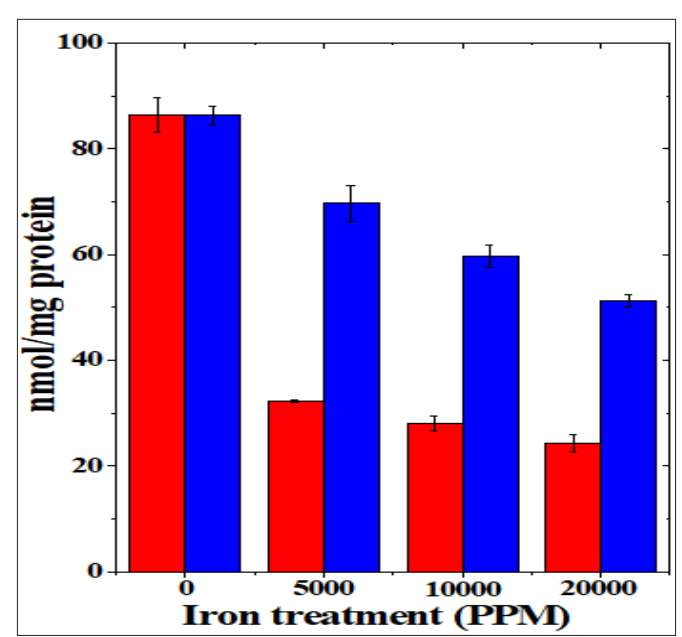

Figure 3: Effect of $250 \mathrm{mg} / \mathrm{kg}$ body weight hesperidin on the catalase activity in mice liver exposed to iron overload. Red Bars: Iron and Blue Bars: Hesperidin+Iron. 


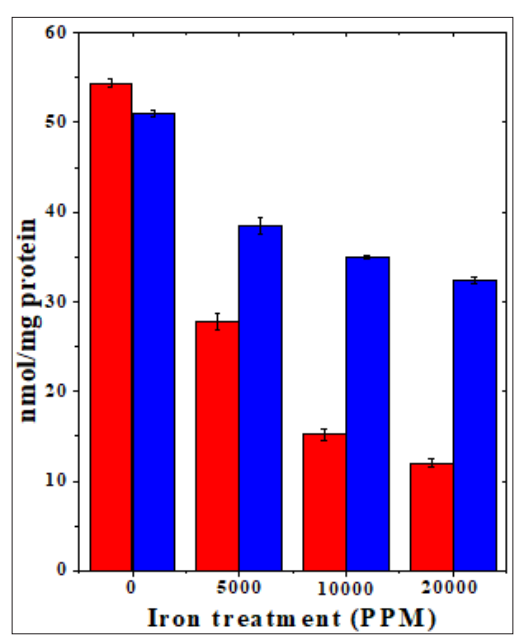

Figure 4: Effect of $250 \mathrm{mg} / \mathrm{kg}$ body weight hesperidin on the superoxide dismutase activity in mice liver exposed to iron overload. Red Bars: Iron and Blue Bars: Hesperidin+Iron.

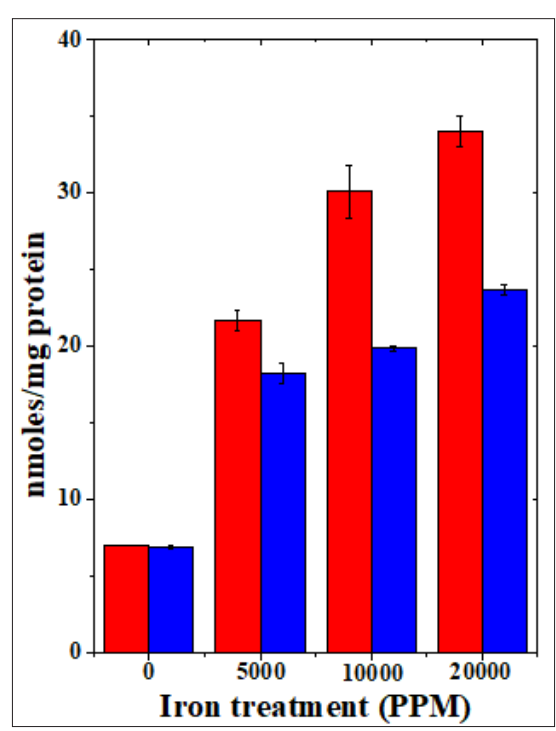

Figure 5: Effect of $250 \mathrm{mg} / \mathrm{kg}$ body weight hesperidin on the iron induced lipid peroxidation in mouse liver. Red bars: Iron and Blue bars: Hesperidin+Iron.

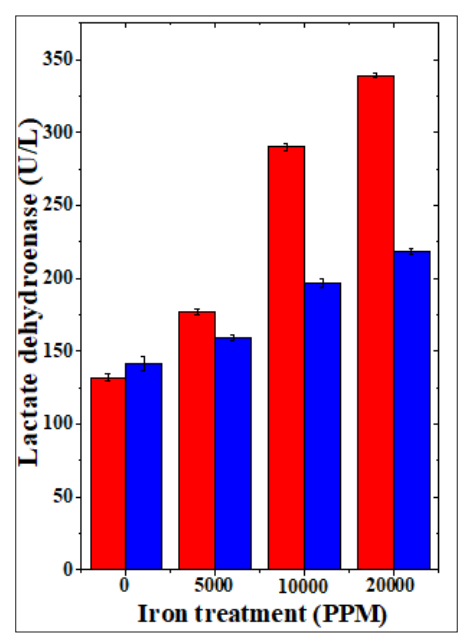

Figure 6: Effect of $250 \mathrm{mg} / \mathrm{kg}$ body weight hesperidin on the lactate dehydrogenase activity in mice liver exposed to iron overload. Red Bars: Iron and Blue Bars: Hesperidin+Iron. 


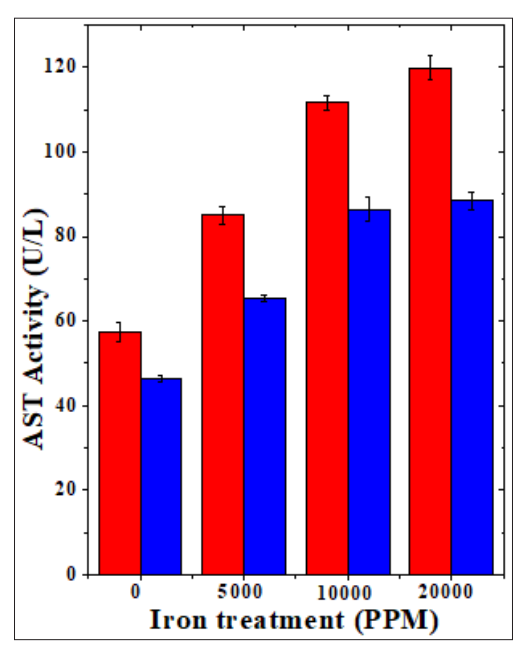

Figure 7: Effect of $250 \mathrm{mg} / \mathrm{kg}$ body weight hesperidin on the aspartate transaminase activity in mice liver exposed to iron overload. Red Bars: Iron and Blue Bars: Hesperidin+Iron.

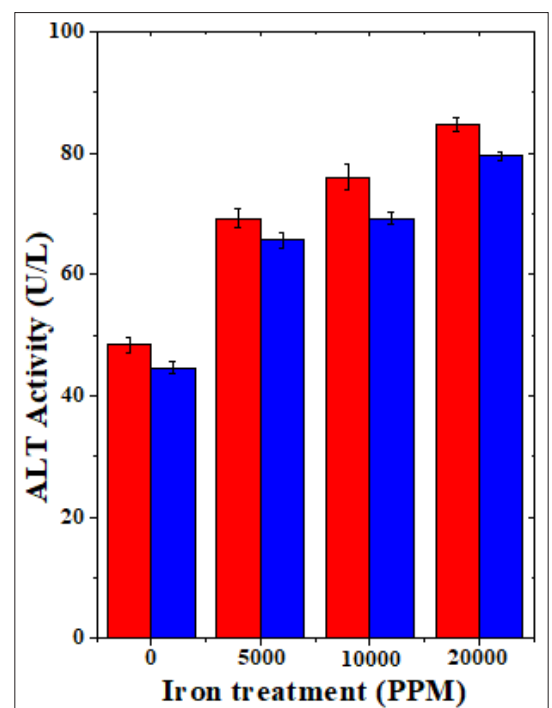

Figure 8: Effect of $250 \mathrm{mg} / \mathrm{kg}$ body weight hesperidin on the alanine aminotransferase activity in mice liver exposed to iron overload. Red Bars: Iron and Blue Bars: Hesperidin+Iron.

\section{Glutathione-S-Transferase}

The spontaneous glutathione-s-transferase activity has been $5.63 \pm 0.41 \mathrm{nmol} / \mathrm{mg}$ protein and administration of hesperidin alone did not alter this activity significantly when compared to nondrug treated control. The chronic administration of ferric chloride for four weeks reduced the glutathione-s-transferase activity significantly in a dose dependent manner and the maximum decline was observed for 20000 ppm iron overload (Table 2) and (Figure 2). Hesperidin treatment before iron overload elevated the glutathiones-transferase activity significantly and the maximum elevation in the GST activity was observed for hesperidin administered in mice before feeding of 5000 ppm iron. With increasing iron overload, the increase in GST activity by hesperidin was lesser (Table 2) and (Figure 2).

\section{Catalase}

The spontaneous catalase activity is $86.360 \pm 3.29 \mathrm{nmol} / \mathrm{mg}$ protein and administration of hesperidin alone did not alter this activity significantly when compared to non-drug treated control. The chronic administration of ferric chloride for four weeks reduced the catalase activity significantly in a dose dependent manner and the maximum decline in the catalase activity was observed for 20,000 ppm iron overload (Table 3) and (Figure 3). Hesperidin treatment before iron overload elevated the catalase activity significantly (Table 3 ) and (Figure 3). This rise in catalase activity was more than two folds for all iron concentrations (Table 3).

\section{Superoxide Dismutase}

The spontaneous superoxide dismutase activity has been $54.35 \pm 0.44 \mathrm{nmol} / \mathrm{mg}$ protein and administration of hesperidin alone did not alter this activity significantly when compared to nondrug treated control. The chronic administration of ferric chloride for four weeks resulted in a drastic decline in the superoxide dismutase activity, which was dose dependent (Table 4). This decline in SOD activity was significant and a maximum decline was 
observed for 20,000 ppm iron overload, where it was greater than four folds in comparison to spontaneous SOD activity (Table 4) and (Figure 4). Hesperidin treatment before iron overload significantly elevated the superoxide dismutase activity and it was two folds higher than the iron treatment alone, except for 5000 ppm (Table 4) and (Figure 4).

\section{Lipid Peroxidation}

The results of present study showed that the levels of spontaneous lipid peroxidation in the liver of mouse has been 6.95 $\pm 0.02 \mathrm{nmol} / \mathrm{mg}$ proteins (Table 5) and (Figure 5). The chronic administration of ferric chloride for four weeks raised the lipid peroxidation significantly when compared to untreated control (Table 5). This increase in lipid peroxidation after iron treatment was greater than two folds and dependent on the dose of iron treatment. The administration of hesperidin alone treatment did not increase the level of lipid peroxidation which was almost similar to the spontaneous level $(6.9 \pm 0.11$ nmoles $/ \mathrm{mg}$ protein). Administration of hesperidin for five days before chronic ferric chloride treatment significantly reduced lipid peroxidation when compared to iron loaded group (Table 5) and (Figure 5).

\section{Lactate Dehydrogenase (LDH)}

The spontaneous LDH activity is $132.063 \pm 3.33$ (IU/L) and administration of hesperidin alone marginally alleviated its activity when compared to non-drug treated control. The chronic administration of ferric chloride for four weeks increased the LDH activity significantly in a dose dependent manner and the maximum rise was observed for 20000 ppm iron overload (Table 7) and (Figure 7). This rise in LDH activity was more than two folds for 10,000 and 20,000 ppm iron treatment (Table 7). Hesperidin treatment for 5 consecutive days before iron overload reduced LDH activity significantly (Table 6) and (Figure 6).

\section{Aspartate Transaminase (AST)}

The spontaneous AST activity is $57.34 \pm 2.39$ (IU/L) and administration of hesperidin alone significantly reduced its activity when compared to non-drug treated control. The chronic administration of ferric chloride for four weeks increased the AST activity significantly in a dose dependent manner and the maximum rise was observed for 20,000 ppm iron overload (Table 7) and (Figure 7). Hesperidin treatment before iron overload reduced the AST activity significantly (Table 7) and (Figure 7).

\section{Alanine Aminotransaminase(ALT)}

The spontaneous ALT activity is $48.44 \pm 1.29$ (IU/L) and administration of hesperidin alone significantly reduced its activity when compared to non-drug treated control (Table 8). The chronic administration of ferric chloride for four weeks increased the ALT activity significantly in a dose dependent manner and the maximum rise was observed for 20,000 ppm iron overload (Table 8) and (Figure 8). Hesperidin treatment before iron overload significantly reduced the ALT activity (Table 8) and (Figure 8).

\section{Discussion}

The iron plays an important role in cellular metabolism due to its transition ability from $\mathrm{Fe}^{2+}$ into $\mathrm{Fe}^{3+}$. Despite the fact that iron is essential in several metabolic functions including energy production it does not exist in free form and it is always found in bound form with proteins [22]. It is an essential micronutrient that regulates oxygen transport in haemoglobin and plays a crucial role in energy production [54]. The total human body iron ranges from 3 to $5 \mathrm{~g}$ and greater than this amount leads to different disorders including anemia, bronchopulmonary dysphasia, cardiovascular and gastrointestinal tract dysfunction, cataract, diabetes, degenerative retinal damage, autoimmune nephrotic syndromes, heavy metal toxicity, Alzheimer's disease, Parkinson's disease, ischemia reflow states, skeletal and respiratory muscle dysfunction and cancer [5565]. The maximum iron is stored in the liver and the accumulation of excess iron induces oxidative stress related disorders, which needs to be alleviated to counter the iron induced oxidative stress. The natural products be of great value in this regard. Therefore, the present study was undertaken to evaluate the ability of hesperidin, a citrus flavanone to reduce the iron-induced oxidative stress in the liver of Swiss albino mice.

Glutathione is a tripeptide, which controls thiol redox reactions and maturation of extra-mitochondrial iron sulphur clusters. Glutathione insulates cytosolic function in iron metabolism by varying its concentration during redox stresses [66]. Glutathione is abundantly present in the cell and it participates in several redox reactions vital to the cell. It protects the cells from a host of endogenous and exogenous toxic insults [67]. The iron concentration is tightly regulated in the cells. However, excess iron triggers the cascade of free radical formation leading to increased oxidative stress [22]. This may be the cause for the dose dependent reduction in the glutathione concentration in the present study by iron overload. Earlier iron overload has been reported to reduce glutathione concentration in vitro [68,69]. Hesperidin treatment arrested the iron induced decline in the GSH concentration in mice liver. The studies regarding the use of hesperidin to protect against the iron-induced glutathione depletion are scanty. However, naringin another citrus flavanone has been reported to reduce iron induced glutathione concentration in vitro $[68,69]$.

Glutathione-s-transferases are a group of detoxifying enzymes, found in all aerobic eukaryotes and they protect cells from the toxic insults by deactivating hydrophobic cytotoxic and genotoxic compounds [70]. The treatment of mice with different doses of iron for one month resulted in a dose dependent decline in the glutathione-s-transferase activity in the liver. A similar effect has been observed in Caucasian patients receiving iron therapy for the treatment of $\beta$-thalassemia, where GSTT1 and GSTM1 genes were downregulated [71]. This indicates that iron overload is detrimental to the glutathione-s-transferase activity due to the ability of iron to induce oxidative stress in the cells. The hesperidin administration has reduced the iron-induced decline in the glutathione-s-transferase activity. There are no reports regarding the use of hesperidin to protect against the iron induced attenuation in the glutathione-s-transferase activity in mouse liver. However, it has been reported to arrest iron-induced decline in glutathione-stransferase activity in rat liver earlier [72].

Catalase or oxidoreductase (EC. .1.11.1.6) is a tetrameric enzyme, which is present in all organisms utilizing oxygen for 
respiration. It detoxifies $\mathrm{H}_{2} \mathrm{O}_{2}$, a strong oxidizing agent involved in tissue pathogenesis by converting it into water and molecular oxygen [73]. The treatment of mice with different doses of iron reduced the activity of catalase in mice liver. A similar effect has been observed in mice liver fed with iron overload diet for four months [74]. Earlier the iron overload has been reported to reduce catalase activity in rat liver [72]. Similarly, iron overload has been reported to attenuate the catalase activity in vitro [68,69]. The hesperidin treatment arrested this decline in the catalase activity by elevating the activity of catalase in mice liver significantly. A similar increase in catalase activity has been reported in rat liver administered with hesperidin earlier [72]. The naringin, a citrus bioflavonoid has been reported to increase the catalase activity in HepG2 cells and isolated liver mitochondria in vitro [68,69].

Superoxide dismutases are ubiquitously present in all organisms that use oxygen for their energy requirement. The aerobic organisms produce superoxide radical during respiration, which is not highly reactive, but it becomes reactive with transition metal complexes of iron, copper and manganese leading to increased oxidative stress $[75,76]$. The superoxide dismutase triggers the dismutation of $02 \bullet-$ into less toxic hydrogen peroxide and acts as first line of defence against oxidative stress $[75,76]$. It also inactivates nitric oxide reducing oxidative stress. The iron overload has reduced the activity of superoxide dismutase in a dose dependent manner in the present study. A similar effect has been reported in rat and mice liver earlier [72,74]. Hesperidin treatment for five days led to an increase in the superoxide dismutase activity in mice liver in the present study. A similar effect has been observed in iron overloaded rat liver treated with hesperidin [72]. Similarly, naringin treatment has been reported to elevate the superoxide dismutase activity in iron overloaded HepG2 cells and isolated mice liver mitochondria in an earlier study $[68,69]$.

The inactivation of hydroxyl and hydroperoxyl radicals leads to the formation of lipid peroxidation. hydroxyl radicals are formed due to the redox cycling of $\mathrm{Fe}^{2+}$ via Fenton reaction, where it reacts with $\mathrm{H}_{2} \mathrm{O}_{2}$ to produce hydroxyl radical. The Haber Weiss reaction regenerates $\mathrm{Fe}^{2+}$ when superoxide radical reacts with $\mathrm{Fe}^{3+}[77,78]$. Liver being the primary site for iron accumulation, it is at an increased risk of iron overload that induces oxidative stress. The increased iron overload has been indicated in liver cancer [79]. Therefore, it is pertinent to assay lipid peroxidation in the iron overloaded mice.

The iron over load has increased the lipid peroxidation in the mouse liver drastically. These observations are in conformation with our earlier reports where iron overload has been reported to accelerate lipid peroxidation in vitro [68,69]. Similarly, an increase in lipid peroxidation has been observed in mice and rat liver after iron overload [72,74,79]. Hesperidin administration for five consecutive days has retarded lipid peroxidation significantly. A similar effect has been observed in iron overloaded rat liver treated with hesperidin [72]. Likewise, naringin has been reported to reduce lipid peroxidation in the HepG2 cells and isolated mice liver mitochondria in vitro $[68,69]$.
The lactate dehydrogenase is a glycolytic pathway enzyme that catalyzes the conversion of lactate to pyruvic acid in the presence of $\mathrm{NAD}^{+}[80]$. The over production of lactate dehydrogenase is hallmark of liver toxicity/damage and organ failure [81,82]. Similarly, the augmented activities of aspartic acid transaminase and alanine aminotransaminase are indicative of liver damage. The iron overload for 30 days has elevated the activities of lactate dehydrogenase, aspartic acid transaminase and alanine aminotransaminase drastically indicative of liver injury. Iron overload has been reported to increase lactate dehydrogenase, aspartic acid transaminase and alanine aminotransaminase in human serum, mice and rat liver $[72,74,83,84]$. Hesperidin treatment for five consecutive days resulted in a significant reduction in lactate dehydrogenase, aspartic acid transaminase and alanine aminotransaminase in the iron overloaded mice liver indicating that hesperidin pretreatment protected mouse liver against the iron-induced insult. A similar effect has been observed in rat liver treated with hesperidin earlier [72]. Diosmin has been reported to reduce lactate dehydrogenase, aspartic acid transaminase and alanine aminotransaminase in iron loaded rat liver [84].

The exact mechanism of action of hesperidin to reduce the iron induced oxidative stress is not known. Hesperidin may have employed multiple mechanisms to reduce the iron-induced oxidative stress in mice liver.

The iron is known to generate free radicals via Fenton and Haber Weiss reactions during different metabolic processes $[77,78]$. The presence of hesperidin before iron overload would have inhibited the generation of iron-induced free radicals leading to alleviation in iron-induced oxidative stress in the mice liver. Hesperidin has been found to suppress various free radicals [45]. The iron overload has been reported to activate IKK $\beta$ leading to transactivation of NF- $\kappa B$, and TNF- $\alpha$ in Kuffer cells of liver [85]. In addition, iron has been also reported to activate COX-II and prostaglandins, which triggers inflammatory cascade leading to pathophysiology [86]. Hesperidin has been reported to suppress the transactivation of NF- $\kappa B$ and COX-II $[87,88]$, which may have also contributed at molecular level to alleviate oxidant status in hesperidin pre-treated group. The transcription activation of Nrf2 inhibits iron accumulation in the mouse liver, the major site of iron storage and metabolism. The hesperidin administration in rats has been reported to stimulate the Nrf2 activation in theirkidney [89]. A similar effect cannot be ruled out in the present study in mouse liver.

\section{Conclusions}

The present study demonstrates that hesperidin treatment reduced iron-induced biochemical toxicity in the liver attenuating, lipid peroxidation, lactate dehydrogenase, aspartic acid transaminase and alanine aminotransaminase in the mice liver accompanied by elevated glutathione, glutathione-s-transferase, catalase and superoxide dismutase levels. This action of hesperidin seems to be mediated by free radical inhibition and suppression of NF- $\kappa B$, COX-II, prostaglandins and TNF- $\alpha$ activation. The activation of Nrf2 signaling pathway may have lead to increased antioxidant status thereby reducing the iron-induced oxidative stress. Our 
study indicates the utility of hesperidin to reduce iron-induced oxidative stress in clinical situation.

\section{Acknowledgement}

This work was supported by a grant no. F4-10/2010(BSR) UGC from the University Grants Commission, New Delhi, India.

\section{References}

1. Aisen P, Enns C, Wessling Resnick M (2001) Chemistry and biology of eukaryotic iron metabolism. Int J Biochem Cell Biol 33: 940-959.

2. Dlouhy AC, Outten CE (2013) The iron metallome in eukaryotic organisms. Met Ions Life Sci 12: 241-278.

3. Hower V, Mendes P, Torti FM, Laubenbacher R, Akman S, et al. (2009) A general map of iron metabolism and tissue-specific subnetworks. Mol Biosyst 5(5): 422-443.

4. Papanikolaou G, Pantopoulos K (2005) Iron metabolism and toxicity. Toxicol Appl Pharmacol 202(2): 199-211.

5. Galaris D, Pantopoulos K (2008) Oxidative stress and iron homeostasis: mechanistic and health aspects. Crit Rev Clin Lab Sci 45(1): 1-23.

6. Abbaspour N, Hurrell R, Kelishadi R (2014) Review on iron and its importance for human health. J Res Med Sci 19(2): 164-174.

7. Ponka P (1999) Cellular iron metabolism. Kidney Int Suppl 69: S2-S11.

8. Xu Z, Shi Z, Li Y (2014) The Crosstalk between Micro RNA and iron homeostasis. Int J Genomic Med 1: 112.

9. Orino K, Lehman L, Tsuji Y, Ayaki H, Torti SV, et al. (2001) Ferritin and the response to oxidative stress. Biochem J 357: 241-247.

10. Zhang C (2014) Essential functions of iron-requiring proteins in DNA replication, repair and cell cycle control. Protein Cell 5(10): 750-760.

11. Gorell JM, Johnson CC, Rybicki BA, Peterson EL, Kortsha GX, et al. (1999) Occupational exposure to manganese, copper, lead, iron, mercury and zinc and the risk of Parkinson's disease. Neurotoxicology 20(2-3): 239247.

12. Yun S, Vincelette ND (2015) Update on iron metabolism and molecular perspective of common genetic and acquired disorder, hemochromatosis. Crit Rev Oncol/Hematol 95(1): 12-25.

13. Zhao Z, Li S, Liu G, Yan F, Ma X, et al. (2012) Body iron stores and hemeiron intake in relation to risk of type 2 diabetes: A systematic review and meta-analysis. PLoS One 7(7): e41641.

14. Hunnicutt J, He K, Xun P (2014) Dietary iron intake and body iron stores are associated with risk of coronary heart disease in a meta-analysis of prospective cohort studies-3. J Nutri 144(3): 359-366.

15. Steiner M, Ocran K, Genschel J, Meier P, Gerl H, et al. (2002) A homozygous HFE gene splice site mutation (IVS5+1G/A) in a hereditary hemochromatosis patient of Vietnamese origin. Gastroenterology 122(3): 789-795.

16. Lok CY, Merryweather-Clarke AT, Viprakasit V, Chinthammitr Y, Srichairatanakool S, et al. (2009) Iron overload in the Asian community. Blood 114(1): 20-25

17. Kell DB (2009) Iron behaving badly: inappropriate iron chelation as a major contributor to the aetiology of vascular and other progressive inflammatory and degenerative diseases. BMC Med Genom 2(1): 2.

18. Fonseca-Nunes A, Jakszyn P, Agudo A (2013) Iron and cancer risk-a systematic review and meta-analysis of the epidemiological evidence. Cancer Epidemiol Biomarkers Prev 23 (1): 12-31.

19. Martines AM, Masereeuw R, Tjalsma H, Hoenderop JG, Wetzels JF, et al. (2013) Iron metabolism in the pathogenesis of iron-induced kidney injury. Nature Rev Nephrol 9(7): 385-398.
20. Peters DG, Connor JR, Meadowcroft MD (2015) The relationship between iron dyshomeostasis and amyloidogenesis in Alzheimer's disease: two sides of the same coin. Neurobiol Dis 81: 49-65.

21. Shen Y, Huang Z, Liu X, Qian J, Xu J, et al. (2015) Iron-induced myocardial injury: an alarming side effect of superparamagnetic iron oxide nanoparticles. J Cell Mol Med 19(8): 2032-2035.

22. Lane DJ, Merlot AM, Huang MH, Bae DH, Jansson PJ, et al. (2015) Cellular iron uptake, trafficking and metabolism: Key molecules and mechanisms and their roles in disease. Biochim Biophys Acta (BBA)-Mol Cell. 1853(5): 1130-1144.

23. Del Rio JA, Gomez P, Baidez AG, Arcas MC, Botia JM, et al. (2004) Changes in the levels of polymethoxyflavones and flavanones as part of the defense mechanism of Citrus sinensis (cv. Valencia Late) fruits against Phytophthora citrophthora. J Agr Food Chem 52(7): 1913-1917.

24. Nogata Y, Sakamoto K, Shiratsuchi H, Ishii T, Yano M, et al. (2006) Flavonoid composition of fruit tissues of citrus species. Biosci Biotechnol Biochem 70(1): 178-192.

25. Crespo ME, Galvez J, Cruz T, Ocete MA, Zarzuelo A (1999) Antiinflammatory activity of diosmin and hesperidin in rat colitis induced by TNBS. Planta Med 65(07): 651-653.

26. Emim JA, Oliveira AB, Lapa AJ (1994) Pharmacological evaluation of the anti-inflammatory activity of a citrus bioflavonoid, hesperidin, and the isoflavonoids, duartin and claussequinone, in rats and mice. J Pharm Pharmacol 46(2): 118-212.

27. Ameer B, Weintraub RA, Johnson JV, Yost RA, Rouseff RL, et al. (1996) Flavanone absorption after naringin, hesperidin, and citrus administration. Clin Pharmacol Therapeut 60(1): 34-40.

28. Miyagi Y, Om AS, Chee KM, Bennink MR (2000) Inhibition of azoxymethane-induced colon cancer by orange juice. Nutr Cancer 36(2): 224-229.

29. Vabeiryureilai M, Lalrinzuali K, Jagetia GC (2015) Determination of antiinflammatory and analgesic activities of a citrus bioflavanoid, hesperidin in mice. Immunochem Immunopathol 1: 107.

30. Ahmadi A, Shadboorestan A, Nabavi SF, Setzer WN, Nabavi SM, et al. (2015) The role of hesperidin in cell signal transduction pathway for the prevention or treatment of cancer. Curr Med Chem 22(30): 3462-3471.

31. Dobiaš L, Petrová M, Vojtko R, Kristová V (2016) Long-term treatment with hesperidin improves endothelium-dependent vasodilation in femoral artery of spontaneously hypertensive rats: The involvement of NO-synthase and Kv channels. Phytother Res 30(10): 1665-16671.

32. Iranshahi M, Rezaee R, Parhiz H, Roohbakhsh A, Soltani F (2015) Protective effects of flavonoids against microbes and toxins: The cases of hesperidin and hesperetin. Life Sci 137: 125-132.

33. Milenkovic D, Deval C, Dubray C, Mazur A, Morand C, et al. (2011) Hesperidin displays relevant role in the nutrigenomic effect of orange juice on blood leukocytes in human volunteers: a randomized controlled cross-over study. PLoS One 6(11): e26669.

34.Zaragoza F, Fdez Corbeira P, Iglesias I, Benedi J (1986) New natural inhibitors of platelet aggregation in vivo. Part I. Citroflavonoids and hesperidin. An Real Acad Farm 52: 497-504.

35. Son HS, Kim HS, Ju JS (1991) Effects of rutin and hesperidin on total cholesterol concentration, transaminase and alkaline phosphatase activity in carbon tetrachloride treated rats. Hanguk Nonghwa Hakhoe Chi 34: 318-326.

36. Galati EM, Monforte MT, Kirjavainen S, Forestieri AM, Trovato A(1994)Biological effects of hesperidin, a citrus flavonoid. (Note I): antiinflammatory and analgesic activity. Farmaco 40(11): 709-712.

37. Loguercio C, D’Argenio G, Delle cave M (1996) Direct evidence of oxidative damage in acute and chronic phases of experimental colitis in rats. Dig Dis Sci 41: 1204-1211. 
38. Tanaka T, Makita H, Kawabata K, Mori H (1997) Chemoprevention of azoxymethane-induced rat colon carcinogenesis by the naturally occurring flavonoids, diosmin and hesperidin. Carcinogenesis 18: 957965.

39. Kawaguchi K, Mizuno T, Aida K, Uchino K(1997) Hesperidin as an inhibitor of lipases from porcine pancreas and Pseudomonas. Biosci Biotech Biochem 61: 102-104.

40. Kawaguchi K, Kikuchi S, Takayanagi K, Yoshikawa T, Kumazawa Y et al. (1999) Colony stimulating factor inducing activity of hesperidin. Planta Med. 65: 365-366.

41. Lee JH, Kim YS, Lee CK, Lee HK, Han SS, et al. (1999) Antiviral activity of some flavonoids on Herpes-simplex virus. Korean Pharmacog 30: 34-39.

42. Cho J (2006) Antioxidant and neuroprotective effects of hesperidin and its aglycone hesperetin. Archives of Pharm Res 29(8): 699-706.

43. Chen MC, Ye YI, Guang JI, Jian, Liu JW, et al. (2010) Hesperidin upregulates heme oxygenase- 1 to attenuate hydrogen peroxide-induced cell damage in hepatic L02 cells. J Agric Food Chem 58(6): 3330-3335.

44. Tamilselvam K, Braidy N, Manivasagam T, Essa MM, Prasad NR, et al. (2013) Neuroprotective effects of hesperidin, a plant flavanone, on rotenone-induced oxidative stress and apoptosis in a cellular model for Parkinson's disease. Oxidat Med cell Long.

45. Jagetia GC, Rao KVNM (2017) Topical application of hesperidin, a citrus bioflavanone accelerates healing of full thickness dermal excision wounds in mice exposed to 6 Gy of whole body $\gamma$-Radiation. Clin Res Dermatol Open Access 4(3): 1-8.

46. Jagetia GC, Rao KVNM (2018) Hesperidin, a citrus bioflavonoid potentiates repair and regeneration of deep dermal excision wounds of mice whole body exposed to different doses of 60Co $\gamma$-radiation. Clin Dermatol J 3(2): 000147.

47. Kawabe M, Tamano S, Shibata MA, Hirose M, Fukushima S (1993) Subchronic toxicity study of methyl hesperidin in mice. Toxicol Lett 69 : 37-44.

48. Sandermann H, Stromiger JL (1972) Purification and properties of C 55-isoprenoidalcohol phosphokinase from Staphylococcus aureus. J Biol Chem 247: 5123-5513

49. Moron MS, Depierre JW, Mannervik B. (1979) Levels of glutathione, glutathione reductase and glutathione S-transferase activities in rat lung and liver. Biochim Biophy Acta 582: 67-78.

50. Habig WH, Pabst MJ, Jakoby WB (1974) Glutathione S-transferases. The first enzymatic step in mercapturic acid formation, J Biol Chem 249 : 7130-7139.

51. Abei H (1984) Catalase in vitro. Methods Enzymol. 105: 121-126.

52. Marklund S, Marklund G (1974) Involvement of the superoxide anion radical in the autooxidation of pyrogallol and a convenient assay for superoxide dismutase. Eur J Biochem 47: 469-474.

53. Ohkawa ON, Yagi K (1979) Assay for lipid peroxides in animal tissues by thiobarbituric acid reaction. Anal Biochem 95: 391-398.

54. Pietrangelo A (2016) Iron and the liver. Liver Int 36 (S1): 116-123.

55. Halliwell B, JMC Gutteridge (1990) Role of free radicals and catalytic metal ions in human disease: an overview. Methods Enzymol 186: 1-85.

56. Chua AC, B Klopcic, IC Lawrence, JK Olynyk D, et al. (2010) Trinder, Iron: an emerging factor in colorectal carcinogenesis, World J. Gastroenterol 16: 663-672.

57. Ward RJ, Zucca FA, Duyn JH, Crichton RR, Zecca L (2014) The role of iron in brain ageing and neurodegenerative disorders. Lancet Neurol 13(10): 1045-1060

58. Neves J, Leitz D, Kraut S, Brandenberger C, Agrawal R, et al. (2017) Disruption of the hepcidin/ferroportin regulatory system causes pulmonary iron overload and restrictive lung disease. EBioMedicine 20: 230-239.

59. Tantiworawit A, Tapanya S, Phrommintikul A, Saekho S, Rattarittamrong, et al. (2016) Prevalence and risk factors for cardiac iron overload and cardiovascular complications among patients with thalassemia in northern Thailand. Southeast Asian J Trop Med Pub Hlth 47(6): 13351342.

60. Rank CU, Petersen J, Birgens HS, Nielsen OJ (2015) Hereditary hyperferritinemia-cataract syndrome. Eur Oncol Haematol (2): 147-149.

61. Stugiewicz M, Tkaczyszyn M, Kasztura M, Banasiak W, Ponikowski P, et al. (2016) The influence of iron deficiency on the functioning of skeletal muscles: experimental evidence and clinical implications. Eur J Heart Fail 18(7): 762-773

62. Gelfand BD, Wright CB, Kim Y, Yasuma T, Yasuma R, et al. (2015) Iron toxicity in the retina requires Alu RNA and the NLRP3 inflammasome. Cell Rep 11(11): 1686-1693.

63. Fleming RE, Ponka P (2012) Iron overload in human disease. New Eng J Med 366(4): 348-359.

64. Swaminathan S, Fonseca VA, Alam MG, Shah SV (2007) The role of iron in diabetes and its complications. Diabet Care 30(7): 1926-1933.

65. Martines AM, Masereeuw R, Tjalsma H, Hoenderop JG, Wetzels JF (2013) Iron metabolism in the pathogenesis of iron-induced kidney injury. Nature Rev Nephrol 9(7): 385-398.

66. Kumar C, Igbaria A, D’autreaux B, Planson AG, Junot C (2011) Glutathione revisited: a vital function in iron metabolism and ancillary role in thiolredox control. EMBO J 30(10): 2044-2056.

67. Aquilano K, Baldelli S, Ciriolo MR (2014) Glutathione: new roles in redox signaling for an old antioxidant. Front Pharmacol 5: 196.

68. Jagetia GC, Reddy TK, Venkatesha VA, Kedlaya R (2004) Influence of naringin on ferric iron induced oxidative damage in vitro. Clin Chim Acta 347(1-2): 189-197.

69. Jagetia GC, Reddy TK (2011) Alleviation of iron induced oxidative stress by the grape fruit flavanone naringin in vitro. Chemico-Biol Interact 190(2-3): 121-128.

70. Hayes JD, Flanagan JU, Jowsey IR (2005) Glutathione transferases. Annual Review of Pharmacol Toxicol 45(1): 51-88.

71. Sclafani S, Calvaruso G, Agrigento V, Maggio A, Nigro VL, et al. (2013) Glutathione $S$ transferase polymorphisms influence on iron overload in $\beta$-thalassemia patients. Thalassemia Rep 3(1): 6.

72. Pari L, Karthikeyan A, Karthika P, Rathinam A (2015) Protective effects of hesperidin on oxidative stress, dyslipidaemia and histological changes in iron-induced hepatic and renal toxicity in rats. Toxicol Rep 2: 46-55.

73. Alfonso-Prieto M, Biarnés X, Vidossich P, Rovira C (2009) The molecular mechanism of the catalase reaction. J Am Chem Soc 131(33): 1175111761.

74. Liu D, He H, Yin D, Que A, Tang L, et al. (2013) Mechanism of chronic dietary overload induced liver damage in mice. Mol Med Rep 7(4): 11731179.

75. Abreu IA, Cabelli DE (2010) Superoxide dismutases-a review of the metal-associated mechanistic variations. Biochim Biophys Acta (BBA)Proteins and Proteomics 1804(2): 263-274.

76. Azadmanesh J, Borgstahl GE (2018) A review of the catalytic mechanism of human manganese superoxide dismutase. Antioxidants 7(2): 25.

77. Kehrer JP (2000) The Haber-Weiss reaction and mechanisms of toxicity. Toxicology 149(1):43-50.

78. Das TK, Wati MR, Fatima-Shad K (2015) Oxidative stress gated by Fenton and Haber Weiss reactions and its association with Alzheimer's disease. Arch Neurosci 2(2). 
79. Fischer JG, Glauert HP, Yin T, Sweeney-Reeves ML, Larmonier N, et al. (2002) Moderate iron overload enhances lipid peroxidation in livers of rats but does not affect NF- $\kappa \mathrm{B}$ activation induced by the peroxisome proliferator, Wy-14,643. J Nutri 132(9): 2525-2531.

80. Jialal I, Sokoll LJ (2015) Clinical Utility of Lactate Dehydrogenase A Historical Perspective. Am J Clin Pathol 143: 158-159.

81. Kotoh K, Kato M, Kohjima M, Tanaka M, Miyazaki M, et al (2011) Lactate dehydrogenase production in hepatocytes is increased at an early stage of acute liver failure. Exp Therapeut Med 2(2): 195-199.

82. Cui J, Xiong J, Zhang Y, Peng T, Huang M, et al. (2017) Serum lactate dehydrogenase is predictive of persistent organ failure in acute pancreatitis. J Crit Care 41: 161-165.

83. Barbosa MC, Santos TE, Souza GF, Assis LC, Freitas MV, et al. (2013) Impact of iron overload on interleukin-10 levels, biochemical parameters and oxidative stress in patients with sickle cell anemia. Rev Bras de Hematol Hemoter 35(1): 29-34.

\section{ISSN: 2574-1241}

DOI: $10.26717 / B J S T R .2018 .08 .001602$

Ganesh Chandra Jagetia. Biomed J Sci \& Tech Res

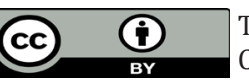

This work is licensed under Creative Commons Attribution 4.0 License

Submission Link: https://biomedres.us/submit-manuscript.php
84. Abdel-Reheim MA, Messiha BA, Abo-Saif AA (2017) Hepatoprotective effect of diosmin on iron-induced liver damage. Int J Pharmacol 13(6): 529-540.

85. She H, Xiong S, Lin M, Zandi E, Giulivi C, et al. (2002) Iron activates NF- $\kappa B$ in Kupffer cells. Am J Physiol Gastrointest Liver Physiol 283: G719-G726.

86. Lousse JC, Defrère $S$, Ramos RG, Van Langendonckt A, Colette $S$, et al. (2009) Involvement of iron, nuclear factor-kappa B (NF- $\kappa$ B) and prostaglandins in the pathogenesis of peritoneal endometriosisassociated inflammation: a review. J Endometriosis 1(1): 19-29.

87. Hirata A, Murakami Y, Shoji M, Kadoma Y, Fujisawa S, et al. (2005) Kinetics of radical-scavenging activity of hesperetin and hesperidin and their inhibitory activity on COX-2 expression. Anticancer Res 25(5): 3367-3374.

88. Ghorbani A, Nazari M, Jeddi-Tehrani M, Zand H (2012) The citrus flavonoid hesperidin induces p53 and inhibits NF- $\kappa$ B activation in order to trigger apoptosis in NALM-6 cells: involvement of PPAR $\gamma$-dependent mechanism. Eur J Nutri 51(1): 39-46.

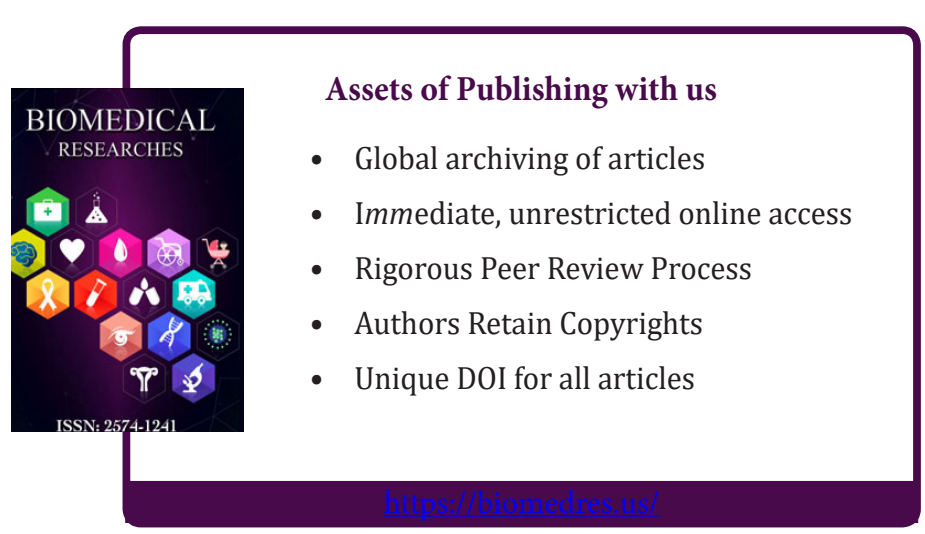

